\title{
Experimental Investigation of spherical food product at different air velocities and radial positions during forced convection cooling
}

\author{
Taliv Hussain*, Ashish Kumar and Ashad Ahmad
}

Mechanical Engineering Department, Aligarh Muslim University, Aligarh, India.202002

*Author corresponding Email:hussaintaliv@gmail.com

\begin{abstract}
Using pre-cooling technique, food products of perishable nature are desired to be conserved from spoiling. Fruits and vegetables and are suggested to be precooled just after harvesting to avoid any food decay. The precooling enhance their storage life and keeps up quality of vegetables and fruits. Thus, an experimental analysis has been carried out to study temperature variation of spherical food product, i.e. mosambi, during the precooling process. In the current study, the effect of three different air velocities, i.e. $4.3,4.8$ and $5.0 \mathrm{~m} / \mathrm{s}$, during precooling of spherical food product has been observed in a forced convection environment. Also, determination of the thermophysical properties of the spherical food product for three different radial positions, i.e. $\mathrm{X}_{\mathrm{C}}=0.042 \mathrm{~m}$ (centre), $\mathrm{X}_{\mathrm{M}}=0.028 \mathrm{~mm}$ (middle) and $\mathrm{X}_{\mathrm{S}}=0.014 \mathrm{~m}$ (surface), has been carried out. The effect of different air velocities and different radial positions on temperature profile of food product was detected. It has been noticed that proper choice of cold air velocity can decrease cooling time of spherical food product, hence resulting in energy saving.
\end{abstract}

Keywords: Precooling, spherical food product, forced convection environment, thermophysical properties, air velocity and radial positions.

\section{Introduction}

The quality of fruits and vegetables should be preserved to improve their trans-regional and global long-distance sales. In the current era of globalization, the fruits grown in one part of world need to be shifted to another due to its demand as it is not nearer to that area. Therefore, various preservation methods are used to carry long distances without losing original flavour and nutrients. The producer must remove field heat from grown vegetables and fruits to advance the economic performance across entire cold chain. This ensures proper handling of product and minimizes losses. The necessity of less temperature does not end here. Temperature needs to be maintained less all over journey till fruit is in hands of ultimate purchaser buying for his consumption. It is impossible to consume produce just after it is harvested; it needs time for crop to be ruined, thus extended shelf life is essential [1]. Preservation ensures this work of enhancing shelf life to two days in few fruits to ten days. Thus it is crucial to upsurge shelf life of produce. As time proceeds, the quality of perishable products declines and hence preservation of those qualities becomes compulsory. The important step in retaining the quality is precooling after harvest to eliminate field heat. Precooling aids in reduction of respiration rate and enzymatic activities. It also slows down microbial growth and thus delays the deterioration of produce. By precooling, moisture loss is minimized, and reduction in ethylene production is allowed; therefore, this slows the ripening and finally improves the quality and shelf life. There are two methods of pre- cooling. They are forced-air precooling and water cooling. Both the methods have their merits and demerits. In forced-air precooling, the air is utilized for cooling. In this cold air, at a certain velocity is flown over product. The air temperature is maintained through an external refrigeration cycle utilizing a refrigerant to cool air. A centrifugal fan is utilized to force air on fruit in forced air cooling method, whereas water cooling in place of air-water is used for cooling. Air is in abundance, and water is limited, so air cooling is preferred over water cooling. Also, chilling losses are fewer in air as compared to water cooling. So most commonly utilized is forced air pre-cooling. One of most effective applications of refrigeration industry is in preservation of perishable food products. Fruits and vegetables are best carriers of vitamins, 
essential fibres, and antioxidants essential for human beings' nutritional health. Fish and meat, primary source of protein, fat, and carbohydrates, are to be preserved during transient and subsequent storage until they are finally consumed. In India, nearly $30 \%$ of perishable items go to waste due to improper preservation facilities. Moreover in developing countries, only a limited quantity of fruits and vegetables are produced for local markets due to a lack of infrastructure and machinery. Reducing high wastage of fruits and vegetables entails various measures to minimize these losses during harvesting, handling, storage, packaging, and processing of fresh vegetables and fruits into suitable products with improved storage features. Cold preservation is most suited method for preserving fruits, vegetables and flesh food products as it retains their original flavour, aroma and texture. Refrigeration controls food products' microbiological, biochemical, and physical processing, thus preventing deterioration and increasing storage life [2].

Lisowa et al. (2002) [3] considered the influence of temperature on thermal properties of apple. They noted that by increasing temperature in range of $273-333 \mathrm{~K}\left(0-6^{\circ} \mathrm{C}\right)$, value of thermal properties increased linearly. Bairi et al. (2005) [4] gave a simple method for calculating thermal diffusivity of different food samples. It was based on analytical solution of 1-D Fourier equation applied to a cylinder. Thermal diffusivity calculated using this method was very precise, and an error of around 4\% was attained. Zou et al. (2006) [5] established airflow and heat transfer models in bulk and layered packaging system. They utilized a porous media approach in which volume averaged transport equations were employed. This approach facilitates development of a modelling system suitable for a wide range of packaging designs. Albyati et al. (2007) [6] considered the effect of air velocity on the temperature profile of the food product. They used apple, papaya and grape as sample food product, which was cooled by blowing air at different velocities $1.6,2.3,3.3,4 \mathrm{~m} / \mathrm{s}$. Three positions, i.e. at $\mathrm{R}=0, \mathrm{R}=\mathrm{d} / 2$ and $\mathrm{R}=\mathrm{d} / 4$, were chosen, and cooling curves were drawn for these positions, and they observed that for all three positions, the curve was exponential. Heat transfer coefficient of the three samples was improved significantly, and the precooling time was reduced and hence less energy consumption. Kumar et al. (2008) [7] executed precooling of orange and tomato for four different airflow velocities. They noted that cooling rate was highest at beginning and decreased in later stage. It was also noticed that air velocity affected cooling rate below dimensionless temperature $\mathrm{T}$ of 0.6 , and critical velocity for orange and tomato was $3.5 \mathrm{~m} / \mathrm{s}$ and $2.6 \mathrm{~m} / \mathrm{s}$, respectively. Increasing cooling velocities above their respective critical velocities does not affect cooling rate significantly. They also correlated to predicting heat transfer coefficient for different air velocities, and prediction error was in an error band of 7.5\%. Ferrua and Singh (2009) [8] executed a numerical analysis of forced air cooling process of retail packages of strawberries. Conservation equations of mass, momentum and energy were solved within system. Their result showed use of a numerical approach as a design tool for optimizing the forced air cooling process of horticulture products. Han et al. (2017) [9] studied how different air inflow velocities affect apple temperature distribution while forced convection cooling of individual apples by simultaneously modeling airflow and heat transfer. It is theoretically correct that increasing air flow velocity can reduce cooling time because of upsurge in cooling rate and heat transfer flux across the apple surface. But after this study, it was concluded that after increasing velocity above $2.5 \mathrm{~m} / \mathrm{s}$, there was a little or no increase in cooling. Thus, keeping in mind amount of energy spent in forced convection beyond $2.5 \mathrm{~m} / \mathrm{s}$ is not favorable for economical cooling.

The present work's main objective is to improve the heat transfer behavior during the cooling of spherical food product in a forced convection environment. In the current study, effect of three different air velocities, i.e. 4.3, 4.8 and $5.0 \mathrm{~m} / \mathrm{s}$ during precooling of spherical food product, i.e. mosambi. Also, determination of thermophysical properties of the spherical food product for three different points $\left(X_{C}=0.042 \mathrm{~m}, X_{M}=0.028 \mathrm{~mm}\right.$ and $\left.X_{S}=0.014 \mathrm{~m}\right)$. Thus, the effect of different air velocities and different radial positions on temperature profile of food product was observed. It has been found that proper choice of cold air velocity can reduce cooling time of spherical food product, thus resulting in energy saving. 


\section{Experimental Set-up}

The forced convection apparatus (figure 1) comprises a chilled air duct with a vapour compression refrigeration unit, air blower, anemometer, and data logger.

- $\quad 1.06 \mathrm{~m} \times 0.6 \mathrm{~m} \times 0.4 \mathrm{~m}$ refrigerated bunker made of $22 \mathrm{~S}$.W.G galvanized iron sheet with a $0.4 \mathrm{~m}$ diameter hole at top and a $0.2 \mathrm{~m}$ diameter hole at bottom end.

- The refrigerant used in the setup is R-22.

- Rotary compressor with 1-ton capacity, Fined-Tube type air-cooled condenser with fan, fins and Copper tube type cooling coil.

- A tapered duct $0.45 \mathrm{~m}$ long was joined from upper hole, and its other end with a 0.2 $\mathrm{m}$ diameter closed duct. The whole duct was then insulated by about $3 \mathrm{~cm}$ thick glass wool.

- Blower was used for air circulation. Air speed inside the duct can be changed using a voltage regulator. Air was recirculated again and again across cooling coils of refrigeration unit.

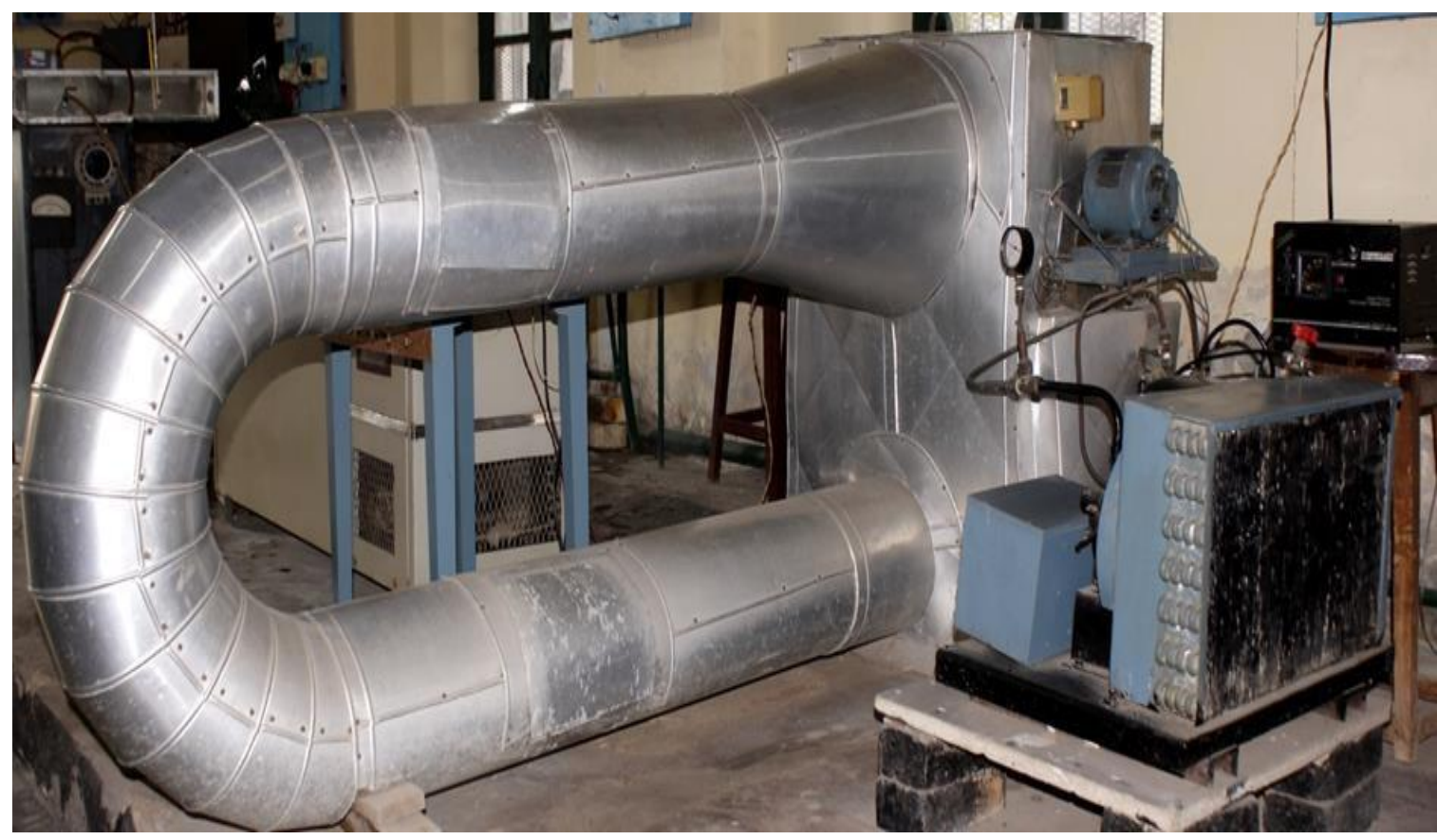

Fig. 1 Forced Convection Cooling Duct

\section{Instruments Used}

\begin{tabular}{|c|c|c|c|c|}
\hline Equipment & Voltage & Sampling Rate & Range & Accuracy \\
\hline $\begin{array}{c}\text { Tweex } \\
8 \text { Channel } \\
\text { Data Logger }\end{array}$ & $\begin{array}{c}\text { Single Phase } \\
220 \text { V Standard } \\
\text { supply }\end{array}$ & $\begin{array}{c}5 \text { seconds to } \\
255 \text { minutes }\end{array}$ & -10 to $+85^{\circ} \mathrm{C}$ & $\pm 0.5^{\circ} \mathrm{C}$ \\
\hline $\begin{array}{c}\text { Digital } \\
\text { Anemometer }\end{array}$ & 3.0 V DC & - & 0 to $30 \mathrm{~m} / \mathrm{s}$ & $\pm 5 \%$ \\
\hline
\end{tabular}

\section{Methodology}

During forced convection, we first start the vapour compression refrigeration unit and air blower in the U duct until a steady low temperature is achieved within the duct. Sample was suspended with the help of a specially fabricated frame and hook in test section. Spherical product temperatures were noted using a data logger. The temperature sensors were inserted into the food product at different points. The temperatures were recorded until the temperature of the product approaches temperature of a cooling medium. The time and temperature were noted for the 
spherical food product mosambi (sweet lemon). The characteristics dimensions of the spherical food product are measured by using a vernier calliper of least count $0.002 \mathrm{~mm}$.

Measured dimensions are as follows:

- $\operatorname{Radius}\left(\mathrm{X}_{1}\right)=0.042 \mathrm{~m} \quad($ Centre $)$

- $\mathrm{X}_{2}=0.028 \mathrm{~m} \quad$ (Middle)

- $\mathrm{X}_{3}=0.014 \mathrm{~m} \quad$ (Surface)

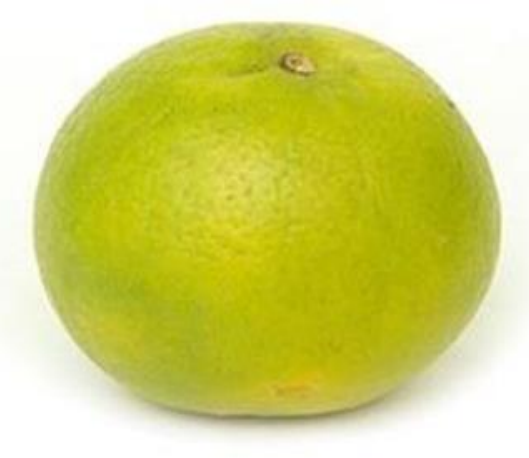

Fig. 2 Food sample (mosambi)

\section{Formulae used}

Thermal conductivity of food product is determined from the known water content, usingthe following empirical co-relation given by Mascheroni \& Calvelo (1980) [10]:

$$
k=0.1075+0.502 W+5.052 * 10^{-4} W . T
$$

Where $\mathrm{W}$ is product water content on a \% mass basis.

Surface film conductance for regular-shaped bodies can be calculated by the following generalized equation by Ansari \& Afaq (1986) [11]:

\section{$\mathrm{Nu}=\mathbf{p}+q \cdot \operatorname{Re}^{\mathrm{r}} \cdot \mathbf{P r}^{\mathrm{s}}$}

The constants p, q, $r$ and $s$ in equation (2) are for spherical food product shown in table 1.

Table 1. Constants in eq. 2

\begin{tabular}{|c|c|}
\hline Constant & Sphere \\
\hline $\mathrm{p}$ & 0.1 \\
\hline $\mathrm{q}$ & 0.3 \\
\hline $\mathrm{r}$ & 0.5 \\
\hline $\mathrm{s}$ & 0.33 \\
\hline
\end{tabular}

$\mathrm{Nu}=$ Nusselt number $\left(=\mathrm{h} \cdot \mathrm{x}_{0} / \mathrm{k}_{\text {air }}\right)$

$\operatorname{Pr}=$ Prandlt number

$\mathrm{Re}=$ Reynolds number $\left(=\mathrm{v} \cdot \mathrm{x}_{0} / \Upsilon\right)$

$\Upsilon=$ kinematic viscosity of air at mean temperature $\left(\mathrm{m}^{2} / \mathrm{s}\right)$

With transient temperature time data, product thermal diffusivity can calculated by the following empirical co relation stated by Gaffeny et al. (1980) [12]:

$$
\tau=[\mathrm{a}+\mathrm{b} \cdot \ln (1 / \mathrm{X}+0.2)-\ln \mathrm{U}] /\left[\mathrm{c} /\left(\mathbf{1}+\mathrm{d} / \mathrm{Bi}^{\mathrm{e}}\right)\right.
$$

The constants a, b, c, d and e are in equation (3) for spherical food product, as shown in table 2. 
Table 2. Constants in eq. 3

\begin{tabular}{|c|c|}
\hline Constant & sphere \\
\hline $\mathrm{a}$ & 0.296 \\
\hline $\mathrm{b}$ & 0.228 \\
\hline $\mathrm{c}$ & 9.870 \\
\hline $\mathrm{d}$ & 2.700 \\
\hline $\mathrm{e}$ & 1.070 \\
\hline
\end{tabular}

\section{Results and discussion}

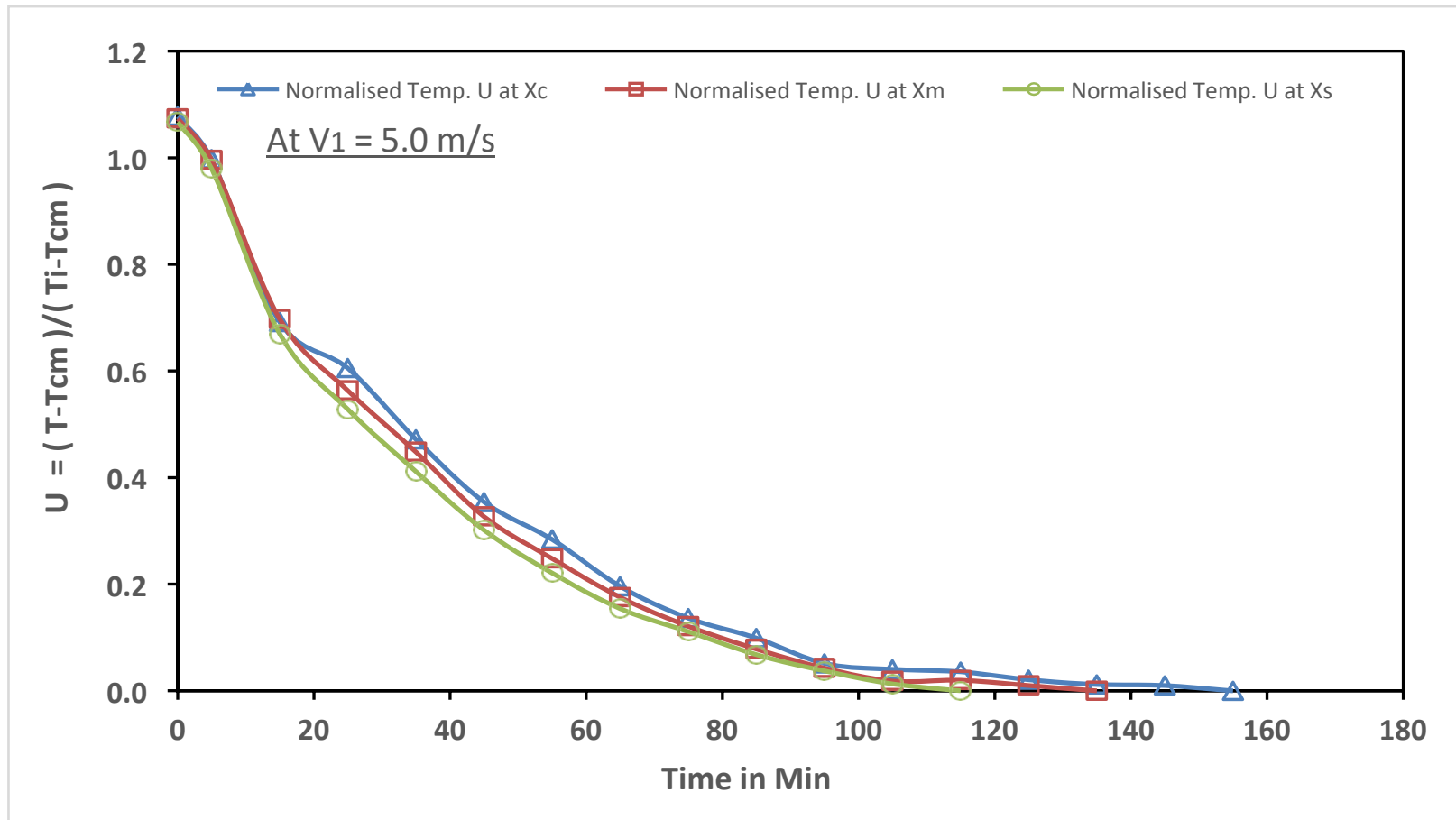

Fig. 3 Variation of dimensionless temperature with time for the precooling of mosambi at $\mathrm{V}_{1}=5.0 \mathrm{~m} / \mathrm{s}$ for different radial positions

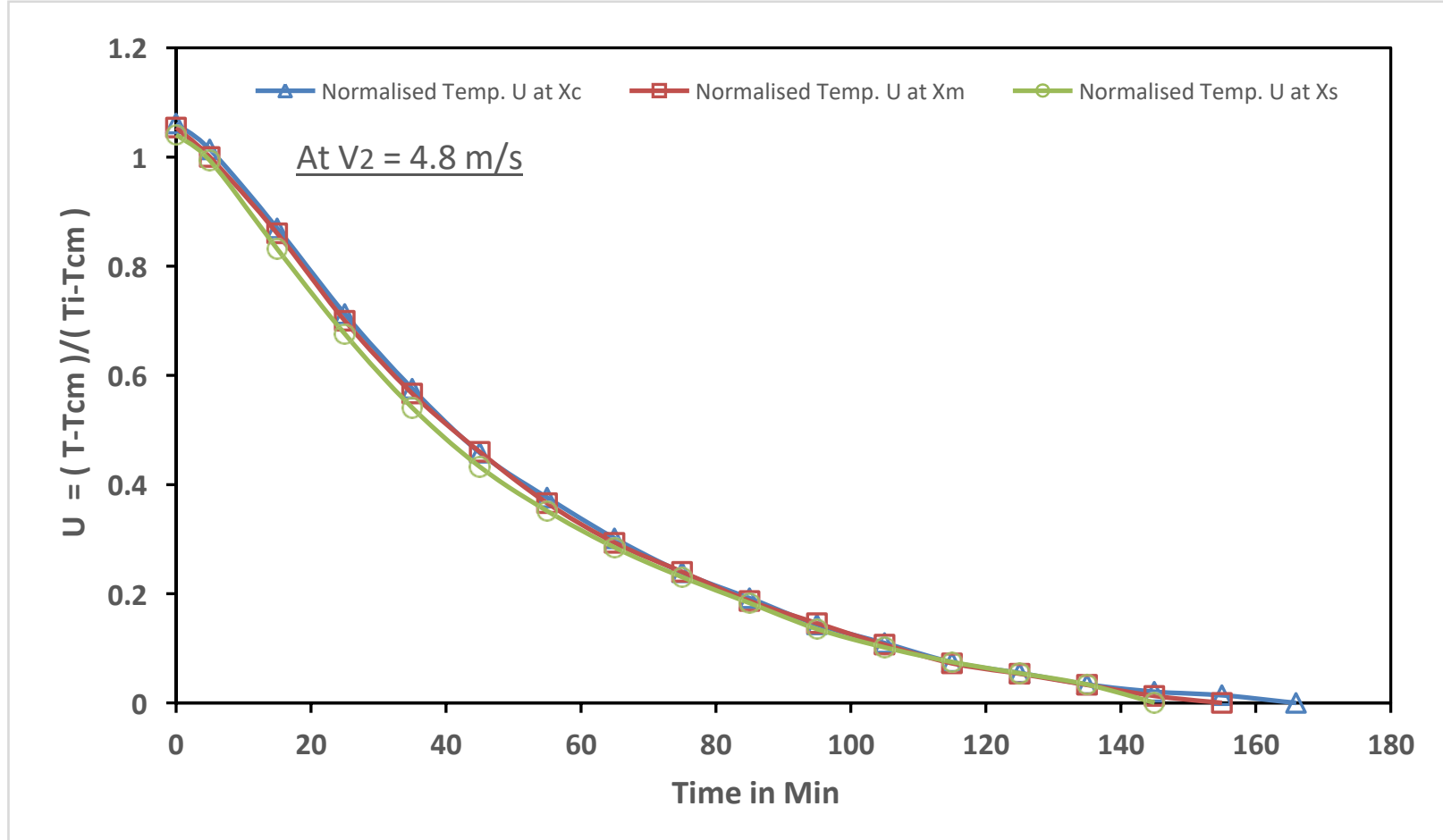

Fig. 4 Variation of dimensionless temperature with time for the precooling of mosambi at $V_{2}=4.8 \mathrm{~m} / \mathrm{s}$ for different radial positions 


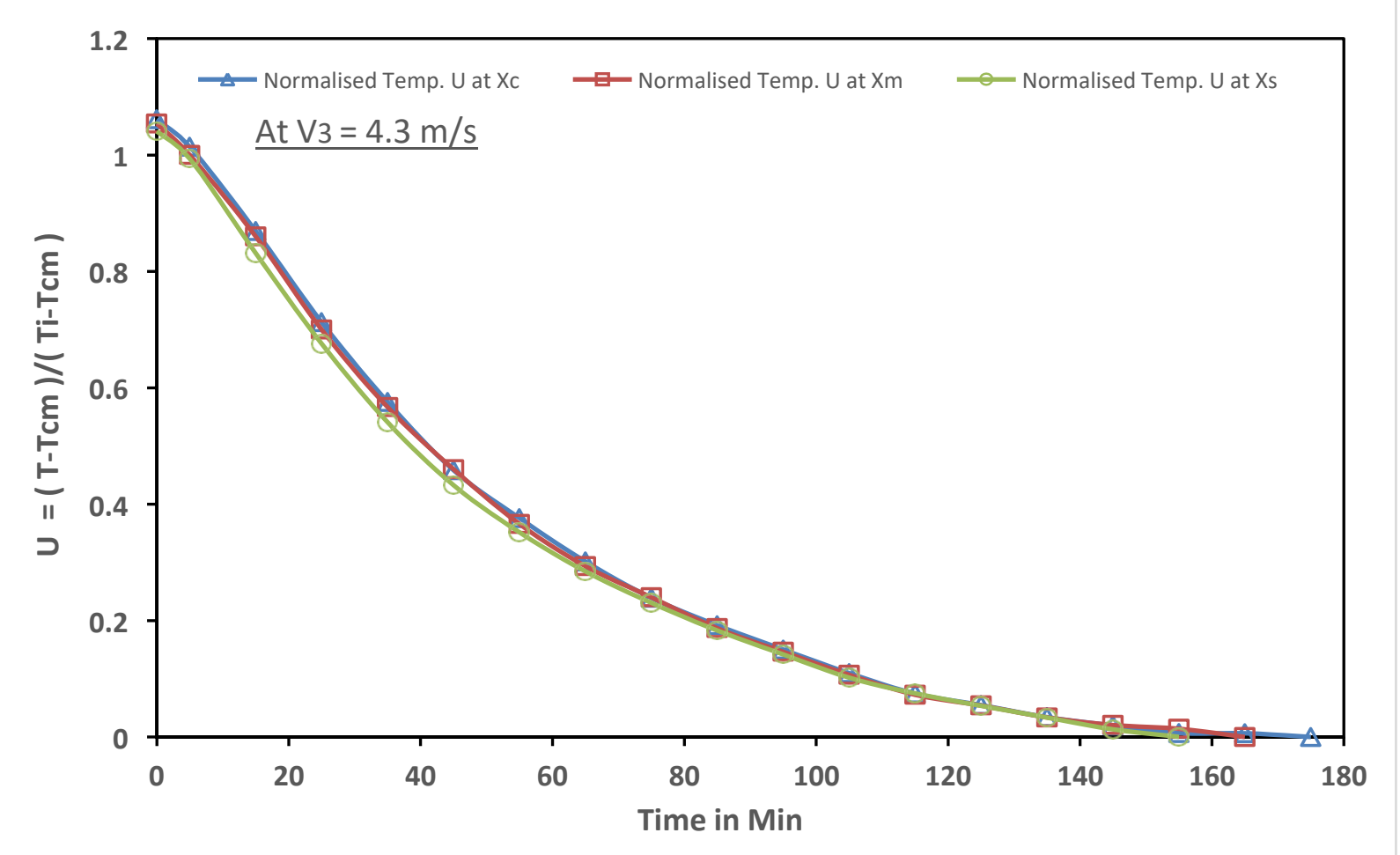

Fig. 5 Variation of dimensionless temperature with time for the precooling of mosambi at $V_{3}=4.3 \mathrm{~m} / \mathrm{s}$ for different radial positions

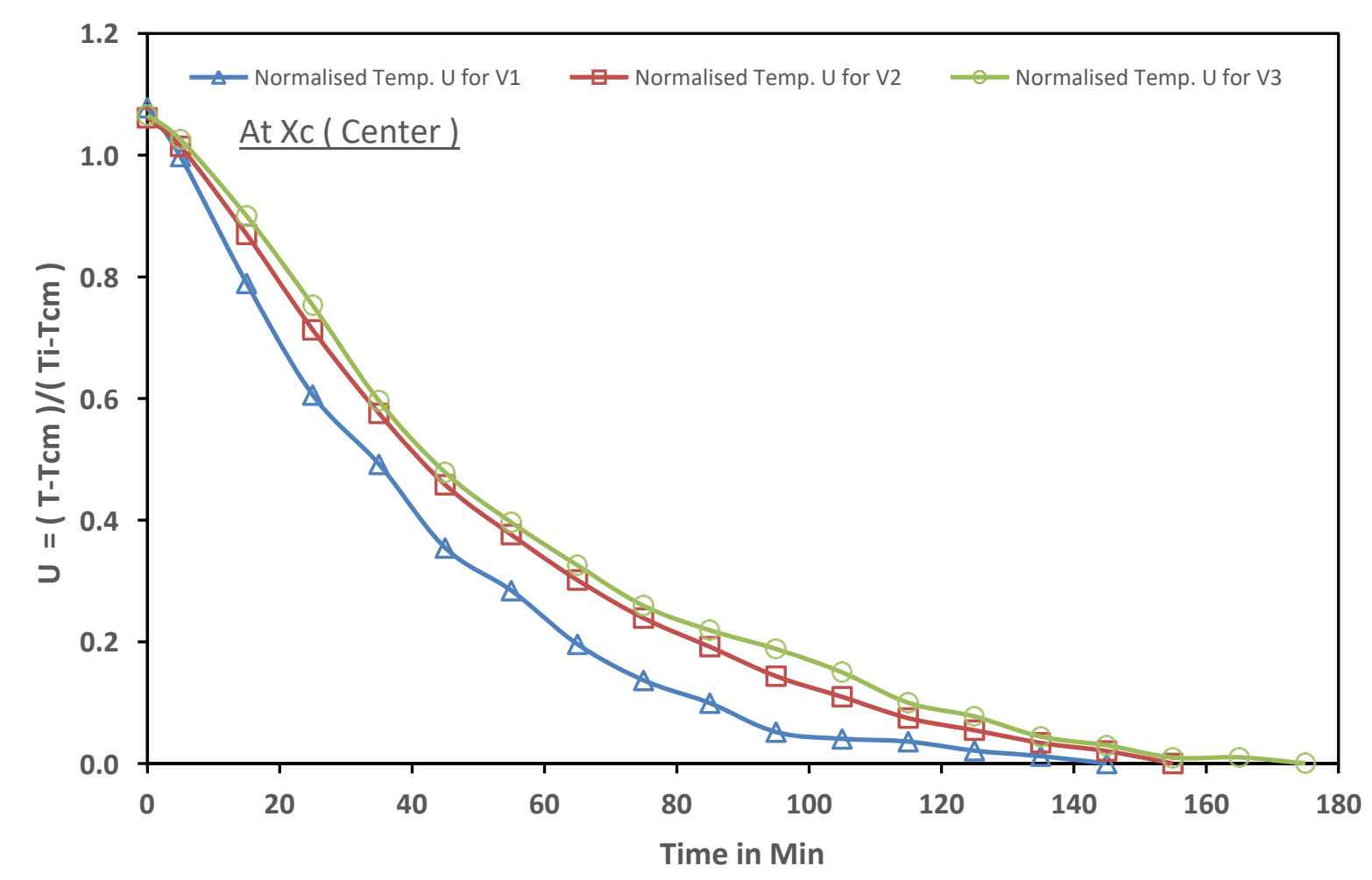

Fig. 6 Variation of dimensionless temperature with time for the precooling of mosambi at Xc (Centre)for different velocities 


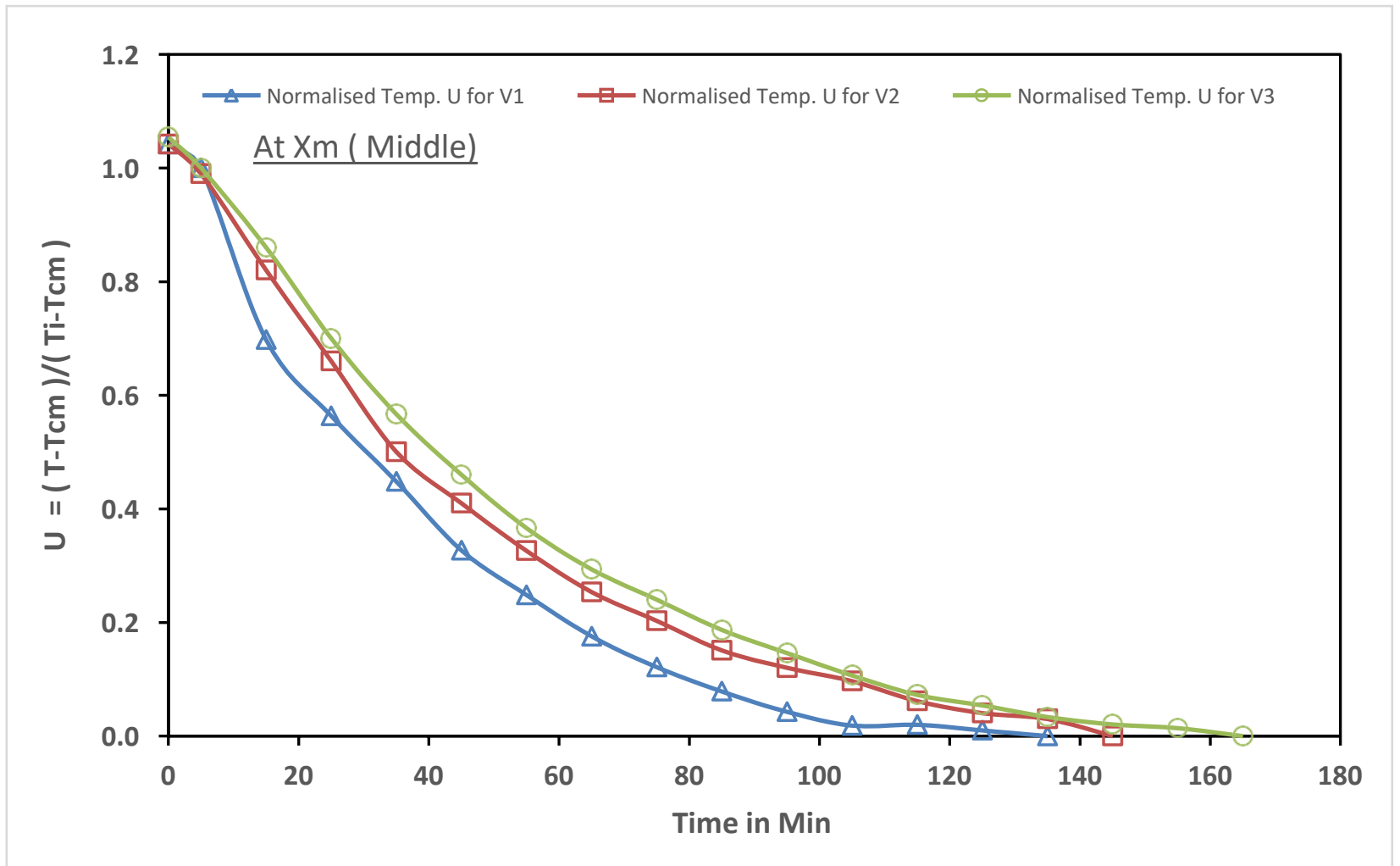

Fig. 7 Variation of dimensionless temperature with time for the precooling of mosambi at $\mathrm{X}_{\mathrm{M}}($ Middle) for different velocities

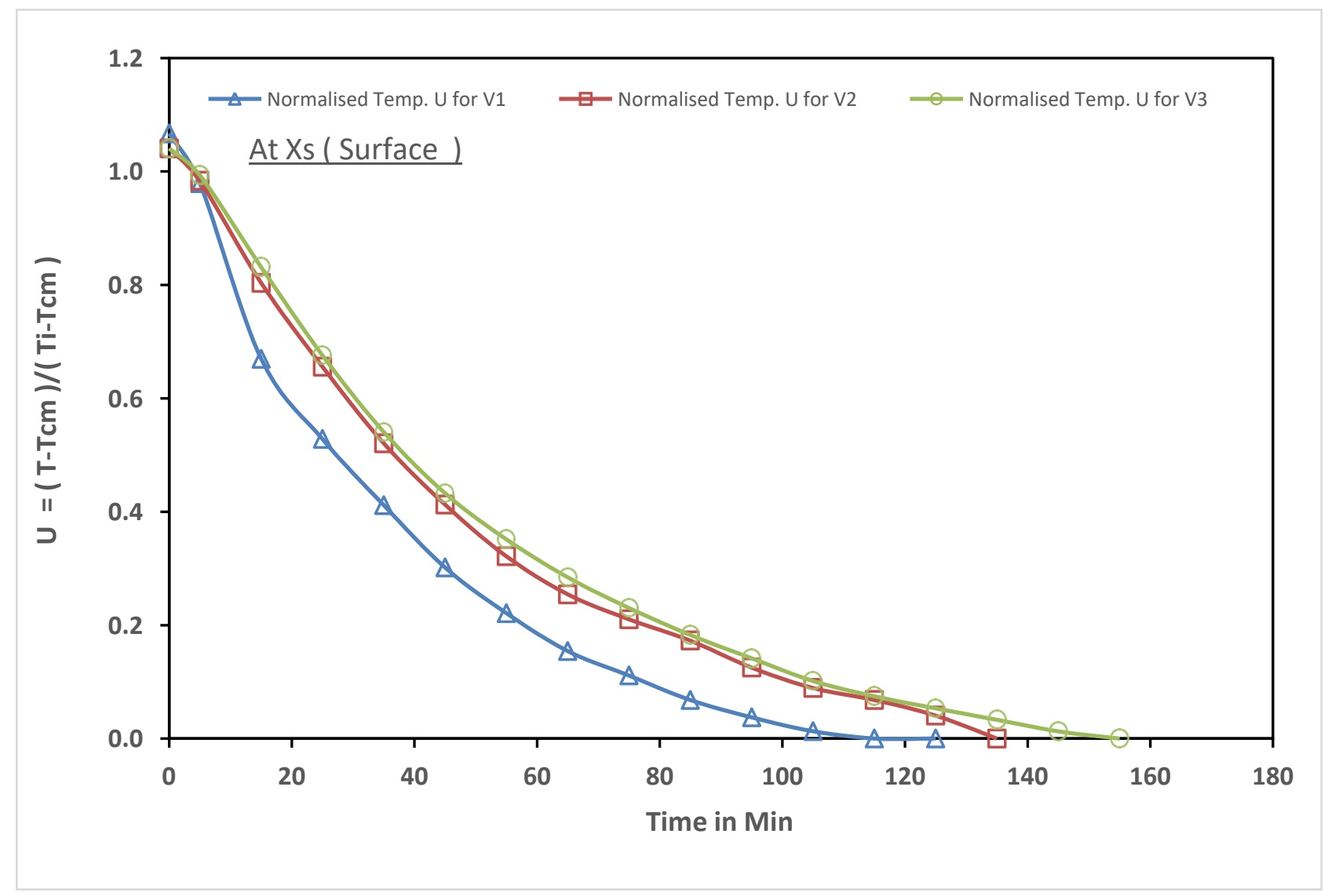

Fig. 8 Variation of dimensionless temperature with time for the precooling of mosambi at Xs(Surface) for different velocities 
Figures (3-5) shows the variation of Normalised temperature (U) vs the time (min) of three radial positions i.e. $\left(X_{C}=0.042 \mathrm{~m}, X_{M}=0.028 \mathrm{~mm}\right.$ and $\left.X_{S}=0.014 \mathrm{~m}\right)$ at three different velocities i.e. $(4.3,4.8$ and $5.0 \mathrm{~m} / \mathrm{s})$. It has been observed in these graphs (3-5) that the centre, middle and surface temperatures of mosambi decreases exponentially with time. There also exists the temperature variation along the radius of the mosambi as well. Initially, the temperature of mosambi at all locations is the same. As the cold air is blown over the surface of mosambi the temperature at all locations starts decreasing. The fall in temperature is more at the surface than at half radius of mosambi. The change in temperature at the centre of mosambi is the least.

Figures (6-8) shows the variation of Normalised temperature (U) vs the time (min) of three different velocities i.e. $(4.3,4.8$ and $5.0 \mathrm{~m} / \mathrm{s})$ at three radial positions i.e. $\left(\mathrm{X}_{\mathrm{C}}=0.042 \mathrm{~m}\right.$, $\mathrm{X}_{\mathrm{M}}=0.028 \mathrm{~mm}$ and $\left.\mathrm{X}_{\mathrm{S}}=0.014 \mathrm{~m}\right)$. It has been observed in these graphs (6-8) Normalised temperature $(\mathrm{U})$ decreases with time as air is blown at different velocities through the food product. As the temperature gradient decreases with time, thus Normalised temperature (U) also decreases. For velocity $(5.0 \mathrm{~m} / \mathrm{s})$, Normalised temperature (U) decreases more.

\section{Conclusions}

Transient heat transfer behaviour during pre-cooling is studied in present work for a spherical food product (mosambi) at $\left(X_{C}=0.042 \mathrm{~m}, X_{M}=0.028 \mathrm{~mm}\right.$ and $\left.X_{S}=0.014 \mathrm{~m}\right)$, for different air velocities $(4.3,4.8$ and $5.0 \mathrm{~m} / \mathrm{s})$. The conclusions drawn based on the above study are as follows:

- Normalised temperature (U) vs time is plotted for different arrangements.

- The centre, middle and surface temperatures of mosambi decreases exponentially with time.

- The fall in temperature is more at the surface than at the centre of mosambi.

- For velocity $(5.0 \mathrm{~m} / \mathrm{s})$, Normalised temperature $(\mathrm{U})$ decreases more.

\section{Nomenclature}

$\mathrm{Bi}=$ Biot number $\left(=\mathrm{h} . x_{o} / \mathrm{k}\right)$

$\mathrm{h}=$ Surface film conductance $\left(\mathrm{W} / \mathrm{m}^{2} . \mathrm{K}\right)$

$\mathrm{k}=$ Thermal conductivity $(\mathrm{W} / \mathrm{m} . \mathrm{K})$

$\mathrm{U}=$ Normalised temperature $\left[=\left(\mathrm{T}-\mathrm{T}_{\mathrm{cm}}\right) /\left(\mathrm{T}_{\mathrm{i}}-\mathrm{T}_{\mathrm{cm}}\right)\right]$

$\mathrm{X}=$ Normalised space coordinate $\left(=\mathrm{x} / x_{0}\right)$

$\mathrm{x}=$ Distance from central plane, central axis or center $(\mathrm{m})$

$x_{o}=$ Half thickness or radius $(\mathrm{m})$

$\mathrm{T}=$ Instantaneous Temperature $\left({ }^{\circ} \mathrm{C}\right)$

$\mathrm{t}=$ Time $(\mathrm{sec} / \mathrm{min})$

$\alpha=$ Thermal diffusivity $\left(\mathrm{m}^{2} / \mathrm{s}\right)$

$\tau=$ Fourier number $\left(\alpha . t / x_{o}\right)$

$\mathrm{Nu}=$ Nusselt number $\left(=\mathrm{h} \cdot \mathrm{x}_{0} / \mathrm{k}_{\mathrm{air}}\right)$

$\mathrm{Pr}=$ Prandlt number

$\mathrm{Re}=$ Reynolds number $\left(=\mathrm{v} \cdot \mathrm{x}_{0} / \Upsilon\right)$

$\Upsilon=$ Kinematic viscosity of air at mean temperature $\left(\mathrm{m}^{2} / \mathrm{s}\right)$

$\mathrm{Xc}=$ At the Centre 
$\mathrm{X}_{\mathrm{M}}=$ At the Middle

$\mathrm{X}_{\mathrm{S}}=$ At the Surface

$\mathrm{cm}$ represents cooling medium and i represents initial

\section{References}

[1] Brosnan, T., \& Sun, D. W. (2001). Precooling techniques and applications for horticultural products - a review. International Journal of Refrigeration, 24(2), 154-170.

[2] Aviara, N. A., \& Haque, M. A. (2001). Moisture dependence of thermal properties of sheanut kernel. Journal of food Engineering, 47(2), 109-113.

[3] Lisowa, H., Wujec, M., \& Lis, T. (2002). Influence of temperature and variety on the thermal properties of apples. International agrophysics, 16(1).

[4] Bairi, A., Laraqi, N., \& de Maria, J. G. (2007). Determination of thermal diffusivity of foods using 1D Fourier cylindrical solution. Journal of Food Engineering, 78(2), 669675.

[5] Zou, Q., Opara, L. U., \& McKibbin, R. (2006). A CFD modeling system for airflow and heat transfer in ventilated packaging for fresh foods: I. Initial analysis and development of mathematical models. Journal of Food Engineering, 77(4), 1037-1047.

[6] Albayati, O. A. Z., Kumar, R., \& Chauhan, G. (2007). Forced air precooling studies of perishable food products. International Journal of Food Engineering, 3(6).

[7] Kumar, R., Kumar, A., \& Murthy, U. N. (2008). Heat transfer during forced air precooling of perishable food products. Biosystems Engineering, 99(2), 228-233.

[8] Ferrua, M. J., \& Singh, R. P. (2009). Modeling the forced-air cooling process of fresh strawberry packages, Part II: Experimental validation of the flow model. International Journal of Refrigeration, 32(2), 349-358.

[9] Han, J. W., Badía-Melis, R., Yang, X. T., Ruiz-Garcia, L., Qian, J. P., \& Zhao, C. J. (2017). CFD simulation of airflow and heat transfer during forced-air precooling of apples. Journal of Food Process Engineering, 40(2), e12390.

[10] Mascheroni, R. H., \& Calvelo, A. (1980). Relationship between heat transfer parameters and the characteristic damage variables for the freezing of beef. Meat Science, 4(4), $267-$ 285.

[11] Ansari, F. A., \& Afaq, A. (1986). Precooling of cylindrical food products. International Journal of Refrigeration, 9(3), 161-163.

[12] Gaffeny, J.J., Baird. C.D and Eshleman, W.D., - Review and Analysis of the Transient Method for Determining Thermal Diffusivity of Fruits and Vegetables. Trans. ASHRAE (1980). 